\title{
Analyzing the Effectiveness of Marketing Strategies in the Presence of Word of Mouth: Agent-Based Modeling Approach
}

\author{
Çiğdem Karakaya, Bertan Badur and Can Aytekin \\ Boğaziçi University, Management Information Systems Department, Istanbul/Turkey
}

\begin{abstract}
Consumer purchasing decision making has been of great interest to researchers and practitioners for improving strategic marketing policies and gaining a competitive advantage in the market.

Traditional market models generally concentrate on single individuals rather than taking social interactions into account. However, individuals are tied to one another with invisible bonds and the influence an individual receives from others, affects her purchasing decision which is known as word of mouth (WOM) effect. In this process, some people have greater influence on other consumers' buying decisions that are known as opinion leaders.
\end{abstract}

A new evolving modeling approach, agent-based modeling enables researchers to build models where individual entities and their interactions are directly represented.

In this paper, we aim to build an agent-based simulation model for a technological product in a monopolistic artificial market. In particular, we will try to assess the efficiency and profitability of different marketing strategies consisting of different price, promotion, quality levels and different number of targeted opinion leaders where consumers are subject to WOM effects . In the presence of WOM, product's quality is found to be the most significant factor affecting the profit of the company due to the positive WOM effect disseminated by the consumers.

Keywords: Consumer network, word of mouth, marketing strategy, agent based modeling

\section{Introduction}

Consumers are the ultimate source of revenue for companies and it is vital to understand consumers in order to gain a competitive advantage in the market. Researchers and practitioners have been delving into the study of consumer behavior for a very long time (Zhang \& Zhang 2007). After the first mention of consumer behavior concept about 80 years ago by the Austrian economist Boehm - Bawerk (Wooliscroft, Tamilia \& Shapiro 2006), a lot of studies and researches are conducted on this subject. According to Solomon (2009), an elementary marketing concept states that organizations exist to satisfy consumers' wants and needs. These wants and needs can only be satisfied by understanding the consumers that will use the product. What, when, why, where

Copyright (C) 2011 Çiğdem Karakaya, Bertan Badur and Can Aytekin. This is an open access article distributed under the Creative Commons Attribution License unported 3.0, which permits unrestricted use, distribution, and reproduction in any medium, provided that original work is properly cited. Contact author: Çiğdem Karakaya e-maill: cigdem.karakaya@boun.edu.tr 
and how a consumer decides to acquire, use and dispose the product are essential questions for understanding consumer behavior (Hoyer \& MacInnis 2007). In addition to consumers' personal preferences and needs, there are psychological and sociological effects that influence the consumers' purchasing decisions. Consumers may purchase a product in order to achieve a social status or to belong to a group. They can make a purchasing decision based on their past experiences or they can communicate with their environment and learn from other consumers (Janssen \& Jager 2001).

Consumers are connected in numerous ways that were not available before. Internet plays a vital role by connecting consumers through social networking sites, blogs, wikis, recommendations sites, etc. (Hennig-Thurau et al. 2010; Wuyts et al. 2010). Individuals are tied to one another with invisible bonds. This forms criss-cross mesh of connections similar to a fishing net (Scott 1988). Each individual receives some kind of resource from the other individual it is connected to. These connections may originate between friends, family members, people whose life standards and interests are similar, people who are physically close to each other or strangers that can reach one another through internet (Libai et al. 2010). In order to understand behaviors of individuals, it is important to understand the dynamics of the network in which they belong.

Information diffusion among the individuals in a network is an important concept for marketers. In a group of people, individuals' attitudes and opinions on an issue change as they get influenced by other members (Friedkin 2003). The influence on an individual that originates from another individual is known to be word-of-mouth (WOM) effect. Companies are taking strategic decisions in order to benefit from the WOM power. Management consultants McKinsey \& Co. estimate that two thirds of the US economy is driven by WOM effect (Dye 2000). In their book "Connected Marketing",
Kirby and Marsden (2006) assert that recent researches have scientifically proven that, high levels of positive WOM derive business growth. Although the WOM effect has been present for a very long time, with the new developments and improvements in technology, it is much more important in influencing individuals buying decisions in recent years (Berry 2005).

Companies spend millions to implement successful strategies to make consumers talk about their products and create an effective WOM (Solomon, Marshall \& Stuart 2008). The advertising agency JWT Worldwide states that, over 85 percent of top 1000 firms use WOM tactics today (Wasserman 2006). Certainly, companies cannot control all the WOM created by the consumers. The motivation to talk about a product and the level of satisfaction retrieved from purchasing the product may vary depending on different consumers. In addition, negative WOM can be created by unsatisfied consumers or by unsuccessful WOM strategy as it happened to McDonalds (Wasserman 2006).

The connections between the individuals represent one individual's attention to the other. Some actors selectively pay attention to other actors, while in some cases everybody pays attention to one person's opinion, for instance, a strong public figure (Lazer 2003). This argument was first introduced by a landmark study by Lazarsfeld, Berolson and Gaudet (1944). It was found that mass media advertisements do not directly influence mass market but instead influence small amount of people who then influence other individuals through WOM. A new term "opinion leaders" is coined then. These people need not necessarily be "leaders" in the usual sense but they are leaders who have direct influence on other individuals due to being exceedingly informed, valued or merely "connected" (Watts \& Dodds 2007). They influence others' behaviors and attitudes because others believe these people have expertise about the product (Rogers 1983). Most of the 
time, they become the first to buy new products and they reduce the uncertainty for other consumers (Solomon, Marshall \& Stuart 2008). The marketing policy of Windows 95 governed by Microsoft has shown the influence and power of opinion leaders (Rosen 2000).

Marketing has been an effective tool and strategy for increasing the sales of a product (Jager 2007). For marketing strategies, companies look for segmentation of its consumers, provision of successful goods and services for each consumer segment and also employment of right promotional tools and pricing strategies to accomplish the company's objectives (Walker, Mullins \& Larreche 2008). Marketing mix is the strategic tool-box that marketers use in order to create a desired response from a set of predefined consumers (Solomon, Marshall \& Stuart 2008). Marketing mix, commonly known as the McCarthy's (1960) 4Ps, consists of product, price, place and promotion. Companies spend effort to find the most efficient marketing mix in order to implement a successful marketing strategy. 4Ps of marketing are essential elements of a marketing strategy, and WOM often complements and extends the effects of promotions and has an effect on the sales of the product. Companies may be underestimating promotion effectiveness by ignoring possible WOM effects (Homan, Legon \& Libai 2004).

Marketing strategies aim at increasing the sales of a company, by the sociological and psychological influences they create on consumers as well. In addition, each distinct individual is influenced in a different level and each individual has the ability to influence other people with their purchase experience. Product characteristics values are also important factors in influencing the buying decision of the consumer. Modern technologies and new marketing strategies evolve over time. The analysis of this complex environment may require different modeling methodologies besides the traditional approach.
Agent based modeling (ABM) is a new analytical tool for social sciences and it enables one to build models where individual entities and their interactions are directly represented (Gilbert 2008). In recent years, $\mathrm{ABM}$ is being utilized as an alternative research methodology in various social sciences; in economics (Tesfatsion \& Judd 2006), sociology (Macy \& Willer 2002), anthropology (Kohler \& Gumerman 2000), politics (Kollman \& Scott 2006), and business (North \& Macal 2007). The modeling approach is applied in sub fields of business; finance (Lebaron 2006), organization (Myong \& Harrington 2006), supply chain management (Valluri, North \& Macal 2009) and in marketing, Journal of Business Research (Gilbert et al. 2007).

$\mathrm{ABM}$ is an efficient tool to model consumer to consumer (C2C) interactions. The study by Ma and Nakamori (2005) defines ABM as an emerging simulation technique that promises to overcome the difficulties of modeling real world situations and managing complex human behavior. Libai et al. (2010) also stress the importance of ABM, as a simulator of "would be world" in which consumers interact with each other and aggregate outcomes of consumer interactions can be observed. ABM is an advantageous tool to use for modeling complex human behaviors aggregating from individual $\mathrm{C} 2 \mathrm{C}$ interactions and testing their reactions to different marketing strategies. It enables one to take into account the complexity of consumer behavior in a social system such as monitoring and handling psychological effects produced by advertisements and WOM effects emerging through consumer networks. Embedding human cognition to agents makes it possible to understand the dynamics of consumers' decision making processes.

Agent based models are increasingly being used in the marketing literature. We can refer to the studies of Jager (2000), Janssen and Jager (1999), Baudisch (2007), Delre et al. (2007) and Kuenzel and Musters (2007) for different implementations of agent based 
models on a variety of subjects. The study of Jager (2000) implements ABM to simulate individual decision making on communal resource usage. Janssen and Jager (1999) uses agent $\mathrm{ABM}$ to model behavioral rules that dominate consumers' decision making processes and study lock - in markets. The study Baudisch (2007) uses ABM to understand consumer heterogeneity in footwear consumption sector, Delre et al. (2007) investigates the consumer behavior on the take off of a new product and the study of Kuenzel and Musters (2007) implement ABM approach for infrequently consumed products.

In this study, we use ABM to evaluate the efficiency of different marketing strategies of a firm producing a technological product in a monopolistic market. In our model, consumer preferences are influenced not only from the quality characteristics of the product but also from WOM effect disseminated from other consumers and opinion leaders. We will analyze the effect of different levels of product characteristics, price, promotion and opinion leader strategies on sales patterns and profitability of the company. We aim to contribute to consumer behavior research by conducting different simulation experiments to find how price, promotion and quality factors are affecting the profitability of the company and assess the importance of WOM in marketing strategies.

The paper is structured as follows: Section 2 briefly reviews ABM, the methodology that is used in this study. Section 3 gives the details of our model. In Section 4, experimental setup of our simulation is presented. Section 5 presents the results of the experiments. The final section concludes the study and discusses the possible further improvements.

\section{Methodology}

In this study we use agent based modeling as our methodology. ABM is a computational simulation method that serves to the study of social sciences. "It is a form of computational social science and it enables a researcher to create, analyze and experiment with models composed of agents that interact within an environment" (Gilbert 2008). Unlike the traditional approach in business research, which mainly focuses on collecting data through surveys, analyzing them and inferring conclusions with the aid of statistical models (Hair et al. 2009), ABM gives one the ability to create agents that have individual heterogeneity and decision rules, space them in a desired geographical or any type of space, connect them through a network for interaction and simulate them to better understand the dynamics of the social system (Gilbert 2008). Although ABM is not a new concept, only in recent years, large amount of studies began to be published. This may be due to significant improvements in computer technology which enables modelers to analyze interacting agents, such as people or firms, and to simulate complex situations.

This promising computational method overcomes the difficulties of conducting experiments in social sciences. In real life, it is usually impossible or unethical to create isolated social systems, and apply treatments to observe the outcomes. ABM allows us to create virtual social systems and conduct experiments repeatedly with different parameters and with randomly varying factors. Given a range of inputs, one can experiment to see how the model behaves, in other words, one can simulate the real world under variety of circumstances (Gilbert 2008).

Agents in the model are autonomous decision making entities (Khouja, Hadzikadic \& Zaffar 2008).

The study of Wooldridge and Jennings (1995) claims an agent, from a more theoretical view of artificial intelligence, is a computer system that is either conceptualized or implemented using the concepts that are more usually applied to humans. 
ABM also gives the opportunity of modeling heterogeneity which means it enables one to model any number of agents that have different attributes with differentiated values (Khouja et al. 2008). Each agent in the model behaves according to her preferences and gets influenced by a motivation function. With the help of ABM we analyze macro behavior emerging from micro behaviors. The study of Ma and Nakamori (2005) claims, "Simple patterns of repeated individual action can lead to extremely complex social institutions".

As human behavior is very complex, finding empirical data on consumer behavior and coping with sociological and psychological ambiguities are difficult. This makes it harder to model with traditional modeling approach. In addition, they do not always act rationally; decreasing the price of a product does not always conclude in increased sales. The study of Deffuant and Huet (2007) claims that, this bounded rational characteristic of human beings makes it harder to define strict rules in modeling.

Human beings learn from their old experiences, get influenced by their social environment, and constitute purchasing decisions based upon their current beliefs and values. Human beings also get affected by marketing strategies such as promotions and advertisements. Traditional market models generally concentrate on single individuals rather than taking social interactions into account (North et al. 2010). Another point is that, they do not comprehend the inner psychological process of consumer purchase decision, such as motivation that measures the degree of consumers' intention to buy a product.

Consumers' attitudes towards a product may change over time depending on the effects of the social network and the perceived social facts (Vag 2007). Psychological effects of advertisements and price changes may also change individual's attitude.
Forecasting market responsiveness to various marketing mix strategies without the presence of actual sales data is a challenging process (Luan \& Sudhir 2010). ABM can be used in situations where there it is hard to collect real life data (Khouja, Hadzikadic \& Zaffar 2008) and it enables researchers to simulate real world environment and obtain possible consequences of various marketing mix decisions in the future, in situations where reliable and high quality data is not available.

The agent based simulation has some disadvantages. These disadvantages mainly derive from the shortcomings of the simulation methodology itself (Banks 1998). First of all, the simulation case needs to be selected very cautiously. The cases which have possible analytical solutions may cause inappropriate use of simulations. One should also be aware that simulation modeling can be very time consuming and the results of the simulation can be difficult to interpret. The outputs of a simulation are mostly results of random inputs, as a result of this situation it might be hard to decide whether an outcome is caused by system interrelationships or randomness. As it is pointed out in the study of Banks (1998), it is possible to overcome these drawbacks of simulation modeling.

Another drawback of agent based simulation is the difficulty of its validation. In most cases, it is hard to acquire suitable and sufficient social science data for systematic validation (Troitzsch 2004). The study of Merson (1998) asserts when there is no sufficient data available for validation as in abstract models, the criteria applied to evaluate theories must be applied to these models. That is, the models need to yield interpretable macro patterns from plausible micro level agent behavioral rules and interactions. The abstract agents based simulation models may be validated by this approach. 


\section{Model}

In our study we analyze the sales pattern and profitability of launching a technological product in a monopolistic market environment using ABM. The company implements different marketing strategies which consist of different promotion and price levels, different quality characteristics of the product and different number of targeted opinion leaders. It has the power to change the quality characteristic and price of the product, as well as the promotion and opinion leader strategy and to monitor WOM effect on profits. We take into account three of the 4Ps, product (quality), price and promotion in the model and ignore the place effect.

The market environment is the place where consumers and products meet. There are $\mathrm{N}$ heterogeneous consumers in the market and they are connected through a social network. In the consumer population there are $\mathrm{M}$ opinion leaders. Opinion leaders have a larger effect on the consumers compared to other people. They are randomly distributed among the population. In other words consumers have the ability to act according to their own preferences and to influence each others' purchasing decisions.

There are $\mathrm{T}$ discrete time steps at each experiment. At each time step the model assess whether an individual already purchased the product or not. If the individual has purchased the product, she uses the product until the last time step and does not make a purchasing decision in consecutive time steps. Otherwise the individual revises her buying decision in every time step. At the beginning of each replication, the population is initialized and the company launches its product into the market.

As the consumer population is created, randomly distributed parameters are assigned to every individual for their product preferences values. Each individual also has sensitivity parameters for price, promotion and WOM which are randomly distributed. These sensitivity parameters show how receptive a consumer is to external factors. Some consumers' quality sensitivity may out weight their price sensitivity, in other words low prices may not persuade some consumers to purchase low quality products (Schwaiger \& Stahmer 2003).

After the consumer population is created, the differences between individual consumers' preferences are calculated. We set preferences as the indicator of distance between individuals assuming that individuals having similar product preferences are more likely to have similar life standards and are more likely to encounter with each other (Carley 2003). The absolute value of the differences between individuals' preference values are used to determine whether they are connected to one another. Individuals that have a distance lower than a predetermined threshold are assumed to be connected. We assume that, consumers connected to each other have the ability to influence each other and an individual is more likely to get influenced by a person who has similar product preferences.

In this study we only take quality as the product decision and we set two technological attributes for the specified product. The product has two different attributes. For the first attribute, consumers may prefer any value depending on their needs. Size can be $\mathrm{n}$ example for this kind of attribute. The second attribute is "the more, the better" type of attribute, which means that consumers are always willing to get higher levels of it, such as resolution of the screen.

Price is the amount the consumer pay in exchange of the product. Even though it may seem that lower prices will attract larger number of consumers, with the adequate promotion strategies, the motivation and 
7 Journal of Marketing Research and Case Studies

perception of the product on consumers may change and consumers may be willing to pay a higher price to own the product. They may also pay more in order to attain a social status or to belong to a group. In this study, we refer to promotion as a policy that is governed to attract more consumers, such as advertisements or campaigns.

The study of Zhang and Zhang (2007) is taken as a reference point to the utility function. There are four components in the utility function of a consumer. These components are quality, promotion, WOM and price. The total utility of the consumer is the sum of these four components. All the parameters used for computing utility components scale from 0 to 1 . The utility function for consumer $i$ is as follows:

$$
\mathrm{U}_{\mathrm{i}}=\mathrm{U}_{\mathrm{i} 1}+\mathrm{U}_{\mathrm{i} 2}+\mathrm{U}_{\mathrm{i} 3}+\mathrm{U}_{\mathrm{i} 4}
$$

Where;

- U i1: utility component of quality for consumer i

- $\mathrm{U}_{\mathrm{i} 2}$ : utility component of promotion for consumer i

- U i3: utility component of WOM for consumer i

- $\mathrm{U}_{\mathrm{i} 4}$ : utility component of price for consumer i

In the first component of the utility function, influence of product quality is gauged. In order to evaluate the product with respect to consumer's preferences, we utilized the approach of Jager (2007).

$$
\mathrm{U}_{\mathrm{i} 1}=\left(\left(\mathrm{G}_{\mathrm{i} 1}+\mathrm{G}_{\mathrm{i} 2}\right) / 2\right) * \mathrm{~K}_{\mathrm{i}}
$$

$G_{i j j}= \begin{cases}1+\left|P_{i j}-A_{j}\right| & \text { if } A_{j}>P_{i j} \text { for consumer } i \text { and product characteristic } j \\ 1-\left|P_{i j}-A_{j}\right| & \text { if } A_{j}<P_{i j} \text { for consumer } i \text { and product characteristic } j\end{cases}$

where;

- $\mathrm{K}_{\mathrm{i}}$ : quality sensitivity of consumer $\mathrm{i}$

- $A_{\mathrm{i}}$ : product characteristic value for attribute i

- $\mathrm{P}_{\mathrm{ij}}$ : preference value of consumer $\mathrm{i}$ for product attribute $j, j=\{1,2\}$

Product attributes change between 0 and 1, 0 being the lowest quality and 1 being the highest quality possible for that attribute.
Cost of the product is linearly related with the quality attributes of the product, so increasing these attributes result in higher costs for the company, since higher quality technology products cost more than lower quality products. For the first attribute, we assumed most of the population (60\%) prefers mid-range values between 0.4 and $0.8,20 \%$ prefers low values between 0.1 and 0.4 and the other $20 \%$ prefers product with values between 0.8 and 1 . Since the second product characteristic is "the more, the better" type of attribute, every reasonable 
consumer will prefer higher values. However, because of the budget limitations they might choose to trade some resolution quality for lower price. For this reason, the preference values are uniformly distributed between 0.6 and 1.

The second component of the utility function consists of the promotion effects. For each time step, the company has the power to define a promotion strategy.

$$
\mathrm{U}_{\mathrm{i} 2}=\mathrm{Pr}_{\mathrm{i}} * \mathrm{C}_{\mathrm{pr}} *\left(\mathrm{PrO}_{\mathrm{t}}+\beta \mathrm{PrO}_{\mathrm{t}-1}\right)
$$

where;

- $\operatorname{Pr}_{\mathrm{i}}$ : promotion sensitivity of consumer $\mathrm{i}$

- $\mathrm{C}_{\mathrm{pr}}$ : constant price sensitivity factor independent of consumer i

- Prot: promotion intensity at time $\mathrm{t}$

- $\beta$ : smoothing constant

Consumers are modeled as having memories so that the effect created by the previous time step's promotion strategy continues to influence consumers to some extent in consecutive time steps. The effect of previous promotion intensity values decays geometrically as in exponential smoothing models. The derived promotion value gets multiplied by the promotion sensitivity value of each consumer at each time step.

In the third component, we cover WOM effect.

$$
\mathrm{U}_{\mathrm{i} 3}=\mathrm{WOM}_{\mathrm{i}} * \mathrm{~S}_{\mathrm{i}} * \mathrm{CWOM}_{\mathrm{WOM}}
$$

where;

- $\mathrm{WOM}_{\mathrm{i}}$ : amount of WOM consumer $\mathrm{i}$ receives

- $\mathrm{S}_{\mathrm{i}}$ : social sensitivity of consumer $\mathrm{i}$

- CWOM: constant WOM sensitivity factor independent of consumer i
Each consumer has different preferences and priorities for the product and gets influenced in different levels by external factors. The satisfaction a consumer receives from consuming the product is the first component of the utility function. This component determines the level and the direction of WOM, a consumer disseminates to others. If the person is an opinion leader, then the influence he or she makes will be three times as powerful as a normal consumer in our experiments. The company must pay a fixed amount of money for each opinion leader it collaborates. Opinion leaders that work with the company do not disseminate negative WOM. We assume that only consumers who have purchased the product create a WOM effect. An important concept is that, even though the consumer purchased the product, he can disseminate negative WOM and hamper other consumers' buying stimuli.

The fourth component of the utility function consists of price.

$$
\mathrm{U}_{4}=-\left(\operatorname{PrSen}_{\mathrm{i}} * \text { price } * \mathrm{C}_{\text {price }}\right)
$$

where;

- $\operatorname{PrSen}_{\mathrm{i}}$ : price sensitivity of consumer i

- price: price of the product

- $\mathrm{C}_{\text {price: }}$ constant price sensitivity factor independent of consumer $\mathrm{i}$

Price and utility has an inverse relationship. Company sets a predetermined price for each time step. This price is multiplied by the consumer's price sensitivity. Consumers with higher budget limits will be less sensitive to price and others will be influenced more by the price of the product, but in any case we assume price is an important attribute in the purchase decision so we randomly assign price sensitivity values to consumers between 0.5 and 1 instead of distributing it evenly between 0 and 1 . 
We use a threshold model for activating the buying decision (Granovetter, 1978). The study of Meyer and Johnson (1999) find that, consumers have a minimum threshold level that must be satisfied to purchase products, but do not have maximum limit. They also claim that, consumers do face a marginal utility decrease resulting from consumption of products that are functionally beyond their requirements. In our study, we set minimum threshold level for consumption but we ignore marginal utility decrease resulting from higher functionality of products.

As it is mentioned before, human beings do not always act rationally and they may not always purchase a product even though it satisfies consumer's expectations. In order to introduce randomness to the consumer decision process, logit function is used to determine the buying decisions of consumers (Anderson, de Palma \& Thisse 1992).

(7)

$$
\operatorname{Logit}(u)=\frac{1}{1+\mathrm{e}^{\mathrm{k}(\mathrm{u}-\alpha)}}
$$

Logit functions are beneficial tools used in social simulations. In Equation 7, u stands for the utility of a particular consumer, $\mathrm{k}$ being the smoothing constant and $\boldsymbol{a}$ being the buying threshold. The logit function ranges from 0 to 1 (Fig.1).

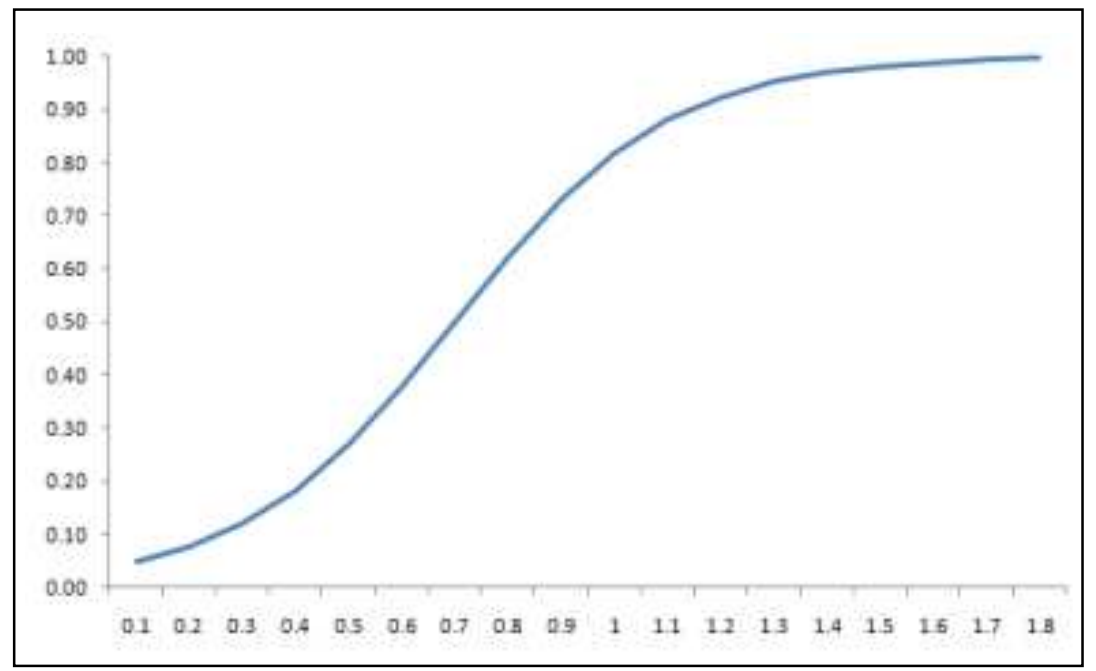

Fig.1: Graph of Logit Function

If the utility of consumer exceeds the threshold value, consumer buys the product with a probability generated by the logit function.

$$
\text { if } U_{i}>\alpha \text { and } \operatorname{logit}\left(U_{i}\right)>=\tau_{i} \text { consumer } i \text { purchases the product }
$$

- $\alpha$ : buying threshold

- $\tau_{\mathrm{i}}$ : random number generated for consumer i
If a consumer buys the product, he uses the product until the last time step and he does not make another purchasing decision in the consecutive time steps. Buyers' utilities do 
not decay due to external factors after purchasing the product.

\section{Experimental Setup}

In this study, our primary aim is to assess the efficiency and profitability of different marketing strategies through simulation experiments. Each experiment, which consists of 20 time steps, is replicated 100 times. In each experiment different parameter setups are governed, in order to monitor the directions and the magnitude of effects of different marketing strategies employed by the company. Each experiment is performed two times, when WOM influence is in effect and not in effect in order to evaluate the importance of WOM effect. The first set of experiments is conducted in the presence of WOM.

The parameters that remain the same in all our experiments are shown in Table1:

Table1: Model Parameter Values

\begin{tabular}{|l|l|}
\hline Parameters & Notation and Values \\
\hline Number of time steps & $\mathrm{T}=20$ \\
\hline Number of consumers in the population & $\mathrm{N}=1000$ \\
\hline Number of opinion leaders & $\mathrm{M}=200$ \\
\hline Productcharacteristics value & $\mathrm{A}_{1}=(0.1-1-1), A_{2}=U^{\sim}(0.6-1)$ \\
\hline Cost of the product & $\mathrm{Cost}_{1} \mathrm{~A}_{1}^{*} 0.1+\mathrm{A}_{2}{ }^{*} 0.2$ \\
\hline Buying threshold & $\mathrm{a}=0.7$ \\
\hline Exponential smoothing constant & $\mathrm{B}=0.5$ \\
\hline Smoothing constant for the logit function & $\mathrm{k}=-5$ \\
\hline
\end{tabular}

There are five different decision variables that affect the buying decision of the consumer. Price, promotion, two design parameters of the product and number of opinion leaders the company chooses to collaborate with. The simulations are run in order to monitor the effects of different product design, price, promotion and opinion leader strategies on profit of the company.

In the first experiment, which is set as the benchmark, a low quality product is created.
The product has for example; a small size and a low resolution for its screen. Product has a high price and low promotion intensity. The company targets 5 opinion leaders. At each new scenario, all the parameters are kept constant except one. In experiment 2 (Exp.2), only the price of the product is modified and in Exp.3, only the promotion intensity is changed.

Parameter values of all the experiments are summarized in Table2. 
Table2: Simulation Experiment Setups

\begin{tabular}{|l|c|c|c|c|c|c|c|}
\hline & Exp.1 & Exp.2 & Exp.3 & Exp.4 & Exp.5 & Exp.6 & Exp.7 \\
\hline Product Char 1 & 0.4 & 0.4 & 0.4 & 0.7 & 0.4 & 0.4 & 0.4 \\
\hline Product Char 2 & 0.4 & 0.4 & 0.4 & 0.8 & 0.4 & 0.4 & 0.4 \\
\hline Price in 20 Time Steps & 0.8 & 0.3 & 0.8 & 0.8 & 0.8 & $0.8^{*}$ & 0.8 \\
\hline $\begin{array}{l}\text { Promotion in 20 Time } \\
\text { Steps }\end{array}$ & 0.4 & 0.4 & 0.9 & 0.4 & 0.4 & 0.4 & $0.4^{* *}$ \\
\hline $\begin{array}{l}\text { Number of Opinion } \\
\text { Leaders }\end{array}$ & 5 & 5 & 5 & 5 & 20 & 5 & 5 \\
\hline
\end{tabular}

*The price is constantly decreased by $2 \%$ at each time step

** The promotion is increased by $2 \%$ at each time step

\section{Results}

In Exp.1 an average of 253 people in the population purchase the product, starting from $216(\mathrm{t}=0)$ and converging to 258 (Fig.2a). The profit of the company for this scenario is found to be 152.89. Each individual is influenced by 41 other individuals on the average and 8 out of 41 are opinion leaders. The cumulative effect of promotion leads a few more consumers to purchase the product in the subsequent time steps, but after the 10th time step, no other consumers purchase the product.

In Exp.2 when price of the product is decreased, in the initial time step, 270 consumers purchase the product and this number rises up to 310 in 20 time steps, 305 being the average (Fig.2-b). When the price of the product is decreased, more people purchase the product in the initial time step. Even though the initial number of buyers is higher compared to the benchmark experiment, after a period of time no more people purchase the product. This may be due to negative WOM buyers emit for the low quality product. In this scenario, the profit of the company decreases to 34.9. Although more people purchase the product, they purchase it for a lower price and the profit of the company decreases. An individual is influenced by 51 other individuals on the average.

When the promotion intensity is increased (Exp.3), the number of buyers in the first time step increases to 369 (Fig.2-c). At the end of 20 time steps, the number of buyers reaches 465. In this setting, there is not enough positive WOM effect, so the number of buyers does not change after time step 8 . Although the cost for the company is higher in this experiment setup, increased promotion has strong influence on stimulating consumers purchasing decision and contributes a significant amount to the company's profit (292).

In Exp.4, the company decides to improve quality characteristics of the product. Keeping all other parameters same as in the benchmark experiment, first product characteristic is changed from 0.4 to 0.7 and second product characteristic from 0.4 to 0.8 . The initial number of buyers increases from 216 to 377 due to the influence of improved product characteristics, and profit increases 
from 153 to 327. Although WOM is positive in this setup due to high product characteristics, the number of buyers stops increasing after a short period of time as in other experiments (Fig.2-d). In the first time step, an individual is influenced by 75 other individuals. In the second time step, this figure significantly increases to 85, explaining that positive WOM induced many other individuals to purchase the product. At the 8th time step, this figure reaches 91 and stays constant afterwards. This can be explained by the fact that, while for most of the consumers, an individual is connected to purchase the product in the first time steps, there may not be enough people left in the consumer's network to purchase the current product and make a positive WOM to trigger other individuals purchasing decisions.

In Exp.5, the company sets its marketing strategy, to reach higher number of opinion leaders. The initial number of buyers increases 228 compared to benchmark and reaches 275 at the end of the scenario (Fig.2e). The profit of the company decreases from 152 to 90 , indicating that when a product does not satisfy consumer preferences, targeting at opinion leaders do not result in significant increase in the number of buyers. In this setup an individual is influenced by 45 other individuals on the average, and only 8 of the 45 are opinion leaders. This indicates that although the company targets increased number of opinion leaders to collaborate with, it fails to convince people to purchase the product when individuals think the product characteristics are below their expectations. The consumers purchasing decisions are not triggered by opinion leaders and the extra cost associated with each opinion leader may cause a decrease in company's profit.

In Exp.6 a decreasing price strategy is governed. The company decreased the price of the product by $2 \%$ at each time step. The number of buyers in the first time step is not different compared to the benchmark experiment. The number of buyers is initially around 216 (Fig.2-f). Falling prices triggers the buying motivation of new individuals. In this setup, the number of consumers that purchased the product increases steadily until the end of the time horizon and reaches 280. Profit of the company (162), is slightly higher than the benchmark experiment. Although the number of buyers is increased, due to the falling prices the profit of the company does not increase dramatically.

Finally, the increasing promotion strategy is tested in Exp.7. The promotion intensity is increased by $2 \%$ at each time step. As with the decreasing price strategy, increasing promotion strategy triggers new individuals purchasing decision and the number of buyers keeps increasing until the last time step (Fig.2-g). This strategy, compared to the benchmark experiment, leads to significant increases in both the number of buyers and profit. Although the associated promotion cost is lower compared to Exp3, in which the promotion intensity is set high and kept constant for all 20 time steps, the profit of the company in this scenario is lower. 
13 Journal of Marketing Research and Case Studies

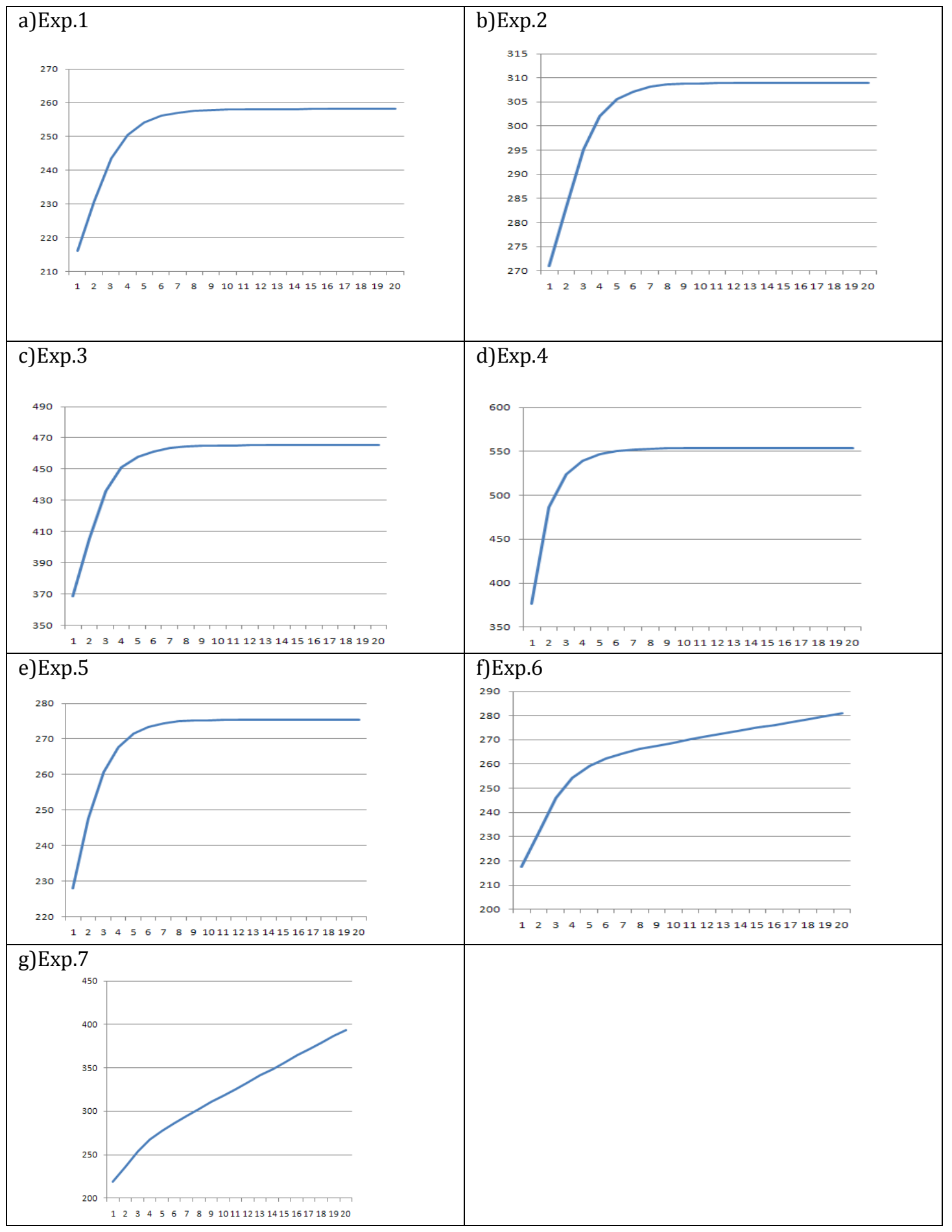

Fig.2:Time Step vs. Number of Buyers for Different Experimental Setups 
As mentioned earlier, each experiment setup is run two times, in the presence and absence of WOM, to assess the WOM influence in consumers buying decision. The experiments' output summary for all scenarios is shown in Table 3.

When the WOM is not in effect, except for Exp.4, number of buyers and the profit of the company increases significantly compared to the corresponding experiments in which WOM is in effect. This result explains how important WOM is and how negative WOM can hamper other individuals buying decisions. In these experiments, cumulative promotion effect leads some increases in the number of buyers in the first time steps and remains ineffective after a period of time.

In Exp.4, where the quality attributes of the product are high, the WOM is positive. Although the number of initial buyers is around 376 both in the absence and presence of WOM, number of final buyers decreases to 490 from 560 at the end of 20 time steps, when WOM is not in effect. The decreased number of buyers leads to a decrease in the profit by 42 .

Table3: Experiment Results for All Scenarios

\begin{tabular}{|c|c|c|c|c|}
\hline & \multicolumn{2}{|c|}{ WOM in effect } & \multicolumn{2}{c|}{ WOM not in effect } \\
\hline & Buyers & Profit & Buyers & Profit \\
\hline $\operatorname{Exp}$ 1 & 253 & 153 & 323 & 208 \\
\hline $\operatorname{Exp}$ 2 & 304 & 35 & 388 & 55 \\
\hline $\operatorname{Exp}$ 3 & 455 & 292 & 590 & 398 \\
\hline $\operatorname{Exp}$ 4 & 539 & 327 & 478 & 285 \\
\hline $\operatorname{Exp}$ 5 & 270 & 90 & 331 & 139 \\
\hline $\operatorname{Exp}$ 6 & 265 & 163 & 347 & 229 \\
\hline $\operatorname{Exp}$ 7 & 318 & 247 & 431 & 360 \\
\hline
\end{tabular}

\section{Conclusion}

In this study we evaluated the influences of different marketing strategies in a monopolistic market and investigated the level of influences of product, price, and promotion and opinion leader strategies on profit of the company. We also aimed to find how product sales patterns evolve over time and profitability of the company changes when WOM is in and not in effect.

When the WOM is in effect, we found that, product quality is the most important factor that influences consumers' buying decisions.
Promotion strategy of the company is the second important factor that triggers consumers buying motivation. Decreasing price and increasing number of opinion leaders to collaborate with do not lead to significant increase in number of buyers, when the product quality is under the consumers' expectations. The results found in the absence of WOM support our findings.

Experiments conducted in the presence and absence of WOM show that, consumers communicate with each other. In the presence of WOM, when the product quality characteristics are low, consumers share this 
information and less people purchase the product. The company should produce higher quality products to increase its profit and avoid negative influence of WOM effect.

As further studies, the model can be extended to include more than one company and product in order to simulate a competitive marketing environment. The optimal time for launching a new product can be investigated and different social network models for consumer interactions can be analyzed.

\section{References}

Anderson, S. P., De Palma , A. \& Thisse, J.-F. (1992). Discrete Choice Theory of Product Differentiation, the MIT Press, Cambridge, Massachusetts.

Banks, J. (1998). "Principles of Simulation," Handbook of Simulation Principles, Methodology, Advances, Applications, and Practice, J Banks (ed.). chapter 1, Wiley- Interscience

Baudisch, A. F. (2007). "Consumer Heterogeneity Evolving From Social Group Dynamics: Latent Class Analyses Of German Footwear Consumption 1980 - 1991," Journal of Business Research, 60 (8). 836-847.

Berry, J. (2005). 'Identifying Reaching and Motivating Key Influencers,' conference paper presented at the Word of Mouth Marketing Association Summit, 29-30 March Chicago.

Carley, K. M. (2003). "Dynamic Network Analysis," Workshop on Dynamic Social Network Modeling and Analysis, National Research Council of the National Academies, 7-9 November, 133-145.

Chang, M.-H. \& Harrington, J. E. (2006). "Agent-Based Models of Organizations," Handbook of Computational Economics, in: LTesfatsion \& KL Judd (ed.). edition 1, volume 2, chapter 26, pages 1273-1337 Elsevier.
Deffuant, G. \& Huet, S. (2007). "Propagation Effects of Filtering Incongruent Information," Journal of Business Research, 60 (8). 816-825.

Delre, S. A., Jager, W., Bijmolt, T. H. A. \& Janssen, M. A. (2007). "Targeting and Timing Promotional Activities: An Agent-Based Model for the Takeoff of New Products," Journal of Business Research, 60 (8). 826835.

Dye, R. (2000). “The Buzz on Buzz,” Harvard Business Review, 78(6). 139-146.

Friedkin, N. E. (2003). "Social Influence Network Theory: Toward a Science of Strategic Modification of Interpersonal Influence Systems," Workshop on Dynamic Social Network Modeling and Analysis, National Research Council of the National Academies, 7-9 November, 89-100.

Gilbert, N. (2008). 'Agent-Based Models,' SagePublications, UK.

Granovetter, M. (1978). "Threshold Models of Collective Behavior," The American Journal of Sociology, 83 (614). 1420-1443

Hair, J. F., Black, W. C., Babin, B. J. \& Anderson, R. E. (2009). Multivariate Data Analysis, Prantice Hall.

Hennig-Thurau, T., Malthouse, E., Friege, C., Gensler, S., Lobschat, L., Rangaswamy, A. \& Skiera, B. (2010). "The Impact of New Media on Customer Relationships," Journal of Service Research, 13 (3). 311-33.

Homan, J. E., Legon, K. N. \& Libai, B. (2004). "Quantifying the Ripple: Word of Mouth and Advertising Effectiveness," Journal of Advertising Research, 271-280.

Hoyer, W. D. \& MacInnis (2007). 'Consumer Behavior,' Houghton, Boston.

Jager, W. (2000). 'Modeling Consumer Behavior,' Rijksuniversiteit Groningen 
Jager, W. (2007). "The Four P's in Social Simulation, A Perspective on How Marketing Could Benefit from the Use of Social Simulation," Journal of Business Research, 60 (8). 868-875.

Janssen, M. \& W. Jager (1999). “An Integrated Approach to Simulating Behavioural Processes: A Case Study of the Lock-In of Consumption Patterns," Journal of Artificial Societies and Social Simulation, 2(2).

Janssen, M. A. \& Jager, W. (2001). "Fashions, Habits and Changing Preferences: Simulation of Psychological Factors Affecting Market Dynamics," Journal of Economic Preferences, 22(6). 745-772.

Khouja, M., Hadzikadic, M. \& Zaffar, M. A. (2008). "An Agent Based Modeling Approach for Determining Optimal Price-Rebate Schemes," Simulation Modeling Practice and Theory, 16 (1). 111-126.

Kirby, J. \& Marsden P. (2006). Connected Marketing: The Viral, Buzz and Word of Mouth Revolution, Butterworth-Heinemann.

Kohler, T. A. \& Gumerman, G. G. (2000). 'Dynamics in Human and Primate Societies: Agent-Based Modeling of Social and Spatial Processes (eds),' Oxford University Press, USA

Kollman, K. \& Page, S. E. (2006). "Computational Methods and Models of Politics," Handbook of Computational Economics, in: L Tesfatsion \& KL Judd (ed.). edition 1 , volume 2 , chapter 29 , pages 1433 1463 Elsevier.

Kuenzel, J. \& Musters, P. (2007). "Social Interaction and Low Involvement Products," Journal of Business Research, 60 (8). 876-883.

Lazarsfeld, P., Berolson, B. \& Gaudet, H. ( 1944). 'The People's Choice,' Columbia University Press, New York.

Lazer, D. (2003). "Information and Innovation in a Networked World," Workshop on Dynamic Social Network
Modeling and Analysis, National Research Council of the National Academies, 7-9 November, 101-118.

LeBaron, B. (2006). "Agent-based Computational Finance," Handbook of Computational Economics, in: L Tesfatsion \& KL Judd (ed.). edition 1, volume 2, chapter 24, pages 1187-1233 Elsevier.

Libai, B., Bolton, R., Bügel M. S., Ruyter, K. O., Götz, O., Risselada, H. \& Stephen, A. T. (2010). "Customer-to-Customer Interactions: Broadening the Scope of Word of Mouth Research," Journal of Service Research, 13(3). 267-282.

Luan, Y. J. \& Sudhir, K. (2010). "Forecasting Marketing Mix Responsiveness for New Products," American Marketing Association, 47, 444-457

Ma, T. \& Nakamori, Y. (2005). “Agent-based Modeling on Technological Innovation as an Evolutionary Process," European Journal of Operational Research, 166 (3). 741-755.

Macy, M. W. \& Willer, R. (2002). "From Factors to Actors: Computational Sociology and Agent Based Modeling," Annual Review of Sociology, 28, 7229-7236

McCarthy, E. J. (1960). 'Basic Marketing: A Managerial Approach,' Homewood, USA.

Merton, R. K. (1968). 'Social Theory and Social Structure (Enl. Ed.),' New York: Free Press

Meyer, R. \& Johnson, E. J. (1995). “Empirical Generalizations in the Modeling of Consumer Choice," Marketing Science, 14(3). G180G189.

North M.J., \& Macal, C. M. (2007). 'Managing Business Complexity: Discovering Strategic Solutions with Agent-Based Modeling and Simulation,' Oxford University Press, USA

North M. J., Macal, C. M., Aubin, J. Thimmapuram, P., Bragen, M., Hahn, J., Karr, 
J., Brigham, N., Lacy, M. E. \& Hampton, D. (2010). "Multiscale Agent-Based Consumer Market Modeling," Wiley Interscience, 15(5). 37-47.

Rogers, E. M. (1983). 'Diffusion of Innovations,' Free Press, USA.

Rosen, E. (2000). 'The Anatomy of Buzz,' DoubleDay Business, New York.

Schwaiger, A. \& Stahmer B. (2003). "SimMarket: Multiagent-Based Customer Simulation and Decision Support for Category Management," Lecture Notes in Computer Science, 2831, 74-84.

Scott, J. (1988). "Social Network Analysis," SAGE Journals, 22 (1). 109-127.

Solomon, M. R. (2009) 'Consumer Behavior: Buying, Having and Being,' Prentice Hall, USA.

Solomon, M. R., Marshall, G. W. \& Stuart, E. W. (2008). Marketing: Real People, Real Choices, Prentice Hall, New Jersey.

Tesfatsion, L. \& Judd, K.L. (2006). "AgentBased Computational Economics: A Constructive Approach to Economic Theory," Tesfatsion L \& Judd KL (ed.). Handbook of computational economics, North Holland Publications, The Netherlands

Troitzsch, K. G. (2004). "Validating Simulation Models," 18th European Simulation Multiconference, SCS Europe.

Vag, A. (2007). "Simulating Changing Consumer Preferences: A Dynamic Conjoint Model," Journal of Business Research, 60 (8). 904-911

Valluri, A., North, M. J. \& Macal, C. M. (2009). "Reinforcement Learning in Supply Chains," International Journal of Neural Systems, 19(5). p331-344.
Walker, O. C., Mullins, J. W. \& Larreche, J. C. (2008). Marketing Strategy: A Decision Focused Approach, MacGraw-Hill, New York.

Wasserman, T. (2006).'Word Games,' Brandweek, 24.

Watts D. J. \& Dodds P. S. (2007). "Influentials, Networks, and Public Opinion Formation," Journal of Consumer Research, vol.34, p 441458.

Wooldridge, M. \& Jennings, N. (1995). "Intelligent Agents: Theory and Practice," The Knowledge Engineering Review, 10 (2). 115152.

Wooliscroft, B., Tamilia, R. D., \& Shapiro, S. J. (2006) A Twenty-First Century Guide to Aldersonian Marketing Thought, Springer, New York.

Wuyts, S., Stremersch, S., Van den Bulte, C. \& Franses, P. H. (2004). "Vertical Marketing Systems for Complex Products: A Triadic Perspective," Journal of Marketing Research, 41(4). 479-487.

Zhang, T. \& Zhang D. (2007). "Agent Based Simulation of Consumer Purchase DecisionMaking and the Decoy Effect," Journal of Business Research, 60 (8). 912-922. 